\title{
Educação jurídica: a importância da cidadania participativa e responsável
}

\section{Legal education: the importance of participatory and responsible citizenship}

Educación jurídica: la importancia de la ciudadanía participativa y responsable

Emilson Pereira dos Reis ${ }^{1}$ Layane Batista de Araújo ${ }^{1}$ Cecilia Maria Resende Gonçalves de Carvalho ${ }^{3}$

${ }^{1}$ Estudante do Curso de Direito, bolsista do Programa de Educação Tutorial Universidade Federal do Piauí. E-mail: emilson-reis@hotmail.com

${ }^{2}$ Estudante do Curso de Direito, bolsista do Programa de Educação Tutorial Universidade Federal do Piauí. E-mail: layanebatista25@gmail.com

${ }^{3}$ Doutora e Bacharel em Direito. Professora titular do Departamento de Nutrição, e tutora do Programa de Educação Tutorial da Universidade Federal do Piauí. Email: ceciliamaria.pop@hotmail.com 
Resumo: Conhecer a Constituição Federal vigente é indispensável para o exercício da cidadania. O presente estudo tem o objetivo de relatar ações educativas e identificar o conhecimento sobre direitos e garantias fundamentais dos escolares do 9 o ano do ensino fundamental de uma escola pública de Teresina. A amostra foi constituída de 24 escolares, idade entre 15 e 18 anos. Os encontros aconteceram semanalmente, com dinamicidade, tendo como referência a cartilha "Constituição em Miúdos" e a própria Constituição Federal de 1988. Os resultados revelaram que os escolares desconhecem a Constituição, seus direitos fundamentais e sociais. Apesar disso, registraram indignação e descontentamento em relação aos aspectos estruturais da escola, foram receptivos e demonstraram interesse pelo assunto. O trabalho possibilitou maior conhecimento da realidade escolar local, revestida de uma troca positiva da teoria com a prática, democratizou o acesso à informação e a dificuldade de êxito entre jovens para o exercício da cidadania.

Palavras-chave: educação; extensão; direitos humanos.

\begin{abstract}
Knowing the current Federal Constitution is indispensable for the practice of citizenship. The present study aims to report educational actions and identify the knowledge about fundamental rights and guarantees of the students of the 9th grade of elementary school in a public school in Teresina. The sample consisted of 24 students, aged between 15 and 18 years. The meetings took place on a weekly basis, dynamically, with reference to the booklet "Constitution in Kids" and the Federal Constitution of 1988. The results revealed that the students are unaware of the Constitution, its fundamental and social rights. Despite this, they showed indignation and discontent regarding the structural aspects of the school, they were receptive and showed an interest in the subject. The work made possible a better knowledge of the local school reality, with a positive exchange of theory and practice, democratizing the access to information and the difficulty of success among young people for the exercise of citizenship.
\end{abstract}

Keywords: education; extension; human rights.

Resumen: Conocer la Constitución Federal vigente es indispensable para el ejercicio de la ciudadanía. El presente estudio tiene el objetivo de relatar acciones educativas e identificar el conocimiento sobre derechos y garantías fundamentales de los escolares del 9o año de la enseñanza fundamental de una escuela pública de Teresina. La muestra fue constituida de 24 escolares, edad entre 15 y 18 años. Los encuentros ocurrieron semanalmente, con dinamicidad, teniendo como referencia la cartilla "Constitución en Cabritos" y la propia Constitución Federal de 1988. Los resultados revelaron que los escolares desconocen la Constitución, sus derechos fundamentales y sociales. A pesar de ello, registraron indignación y descontento en relación a los aspectos estructurales de la escuela, fueron receptivos y mostraron interés por el asunto. El trabajo posibilitó un mayor conocimiento de la realidad escolar local, revestida de un intercambio positivo de la teoría con la práctica, democratizó el acceso a la información y la dificultad de éxito entre jóven.

Palavras clave: educación; extensión; derechos humanos. 


\section{INTRODUÇÃO}

A atual conjuntura política e econômica na qual está imersa a sociedade brasileira, marcada por grandes instabilidades, acabou por provocar intensos debates e reflexões acerca do papel dos dispositivos normativos que regem a vida em sociedade, a contar pela Constituição Federal de 1988. Desse cenário, coloca-se como situação-problema a seguinte: de que maneira o ensino da Constituição Cidadã será capaz de transformar a realidade de uma comunidade escolar, marcada pela ausência de uma cultura em cidadania participativa e responsável?

Ainda sob a égide da Constituição Cidadã, especialmente na órbita do direito à educação, é inegável que o papel da escola não se restringe a tão somente levar o conhecimento ao educando, ensinar princípios, conceitos e fundamentos do ensino regular tradicional. A aprendizagem das noções de direitos e garantias fundamentais, como conjunto de valores que gravitam em torno da dignidade humana, na atualidade, se mostra imprescindível, pois ela repercute nos importantes campos da cidadania participativa e responsável, ambos pilares de qualquer regime democrático.

Nessa perspectiva, cumpre salientar que a Constituição Brasileira assim como outros documentos legais, tais como a Lei de Diretrizes e Bases da Educação Nacional, o Estatuto da Criança e do Adolescente, exigem que os sistemas de ensinos preparem os alunos para o pleno desenvolvimento, bem como para terem participação ativa na sociedade e na qualificação profissional. A esse respeito, diz-se que o ensino da Constituição deve estar alicerçado de instrumentos que favoreçam a compreensão da realidade, de tal sorte que os escolares possam ter uma percepção crítica no exercício pleno da cidadania.

Assim, tendo em vista a complexidade e a gama de direitos albergados na CF 88, optou-se por definir como objeto central de estudo o conhecimento dos alunos acerca dos direitos e garantias fundamentais, normatizados no título II, capítulos I e II, da Constituição Cidadã, cuja intitulação é "Dos direitos e deveres individuais e coletivos e Dos direitos sociais".

O projeto de extensão "Educação jurídica direcionada para estudantes

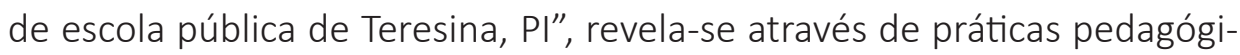
cas que permitam aos escolares pensarem de que forma a sociedade se estrutura, quais direitos e garantias Ihes são assegurados enquanto sujeitos e 
sujeitas de direitos, assim como os respectivos deveres perante a sociedade. Tal sentimento, como se pretenderá demonstrar a seguir, e que balizou o referido projeto de extensão, buscou inserir os estudantes em atividades que os trouxessem reconhecimento como sujeitos ativos e participantes de uma sociedade múltipla e democrática.

O objetivo deste artigo é descrever o conhecimento básico dos estudantes do ensino fundamental acerca dos direitos e garantias fundamentais consagrados constitucionalmente, e demonstrar por meio de ações educativas a importância dessa temática na construção da cidadania no curso da formação escolar, buscando explorar suas potencialidades e desafios.

\section{FUNDAMENTAÇÃO TEÓRICA}

Como explicitado em situação anterior, o ensino da Constituição Cidadã constitui relevante base para o engrandecimento da cidadania participativa. Dessa forma, esse documento de construção coletiva vem desenvolvendo papel ímpar na retomada das ações e políticas públicas com vistas à construção de um Estado Social, já que propõe a ampliação tanto dos direitos e garantias fundamentais do cidadão, quanto das liberdades civis (BRESSAN; COMERLATTO, 2015). Como se pode constatar, há um rol extenso de direitos e garantias fundamentais na Constituição do Brasil de 1988, contudo muito desses direitos não tem eficácia direta e imediata na esfera individual, tornando o texto constitucional, nos dizeres de Canotilho (1982), uma constituição dirigente, que necessita da participação efetiva de seus cidadãos para que suas garantias se materializem na realidade.

\section{EDUCAÇÃO E CIDADANIA}

A cidadania é manifestamente um termo relacionado à vida em sociedade, teve seu primórdio nas civilizações antigas greco-romanas, em que os cidadãos dispunham de direitos e também deveres. Assim, mesmo que nem todos possuíssem o título de cidadãos, foi nessas civilizações que surgiram os primeiros passos para a consolidação da cidadania.

Nesse sentido, foi que, na tentativa de proporcionar direitos e deveres iguais entre os homens, as Revoluções Americana e Francesa 
manifestaram-se positivamente, sobretudo ao considerar a igualdade de todos perante a lei reforçando os ideais democráticos. Ainda sobre essas duas revoluções, apontam Pinsky e Pinsky (2013), da sua importância na afirmação da cidadania das minorias excluída no mundo ocidental, pois, desse momento em diante, todos os tipos de luta foram travados para que se ampliasse o conceito e a prática de cidadania.

A Organização Mundial das Nações Unidas fez, portanto, a partir do olhar do homem como ser universal, a Declaração Universal dos Direitos Humanos, um documento universal que rege e orienta as questões relativas aos direitos humanos como a mais alta aspiração do ser humano comum, pois incorporou o conceito de justiça social para acabar com os abusos a todo o globo terrestre quando considerou que os todos os homens possuem direitos iguais e inalienáveis (BRITO, 2014).

A partir de então, tornou-se referência aos estudos que enfocam a política e as próprias condições de seu exercício, tanto nas sociedades antigas quanto nas modernas. Por outro lado, as mudanças nas estruturas socioeconômicas, incidiram, igualmente, na evolução do conceito e da prática da cidadania, moldando-os de acordo com as necessidades de cada época (MIGUEL et al., 2012).

Seguidamente à análise do conceito de cidadania a partir de um contexto histórico, é necessário concatenar com a importância da educação para sua consolidação. Segundo Palma Filho (1998), a educação escolar está a serviço de um determinado tipo de cidadania, dependendo do tipo educacional que se desenrola na triangulação professor-aluno-conhecimento, ampliando a compreensão do educando em relação ao meio natural ou socialmente criado onde vive para, assim, atuar de um modo não coercitivo, contribuindo para a formação de um indivíduo crítico/reflexivo.

A educação, portanto, deve servir de base para direcionar o entendimento do indivíduo acerca da cidadania de forma tal que, além de dominar seu conceito, possa praticá-la efetivamente, a partir da sua percepção como sujeito de direito e, conhecedor de seus deveres. Para tanto, efetivar a cidadania em todos os âmbitos da sociedade é tarefa de todos os sujeitos em conjunto.

Bobbio, nesse sentido, afirma que: 
[...] a democracia não se refere só à ordem do poder público do Estado, mas deve existir em todas as relações sociais, econômicas, políticas e culturais. Começa na relação interindividual, passa pela família, a escola e culmina no Estado. Uma sociedade democrática é aquela que vai conseguindo democratizar todas as suas instituições e práticas. (BOBBIO, 2002, p. 36).

Como processo de construção coletiva em todas as esferas da sociedade, a cidadania deve ser vista sob uma perspectiva plural e dialógica. Assim, torna-se fundamental a interação e a colaboração entre as instituições educativas formais, as instituições estatais e as diversas organizações e movimentos da sociedade civil, contextos por excelência de educação não formal na cidadania (MARTINS; MOGARRO, 2010).

É oportuno ressaltar que o ato de educar representa muito mais do que simplesmente transferir o conhecimento científico, na verdade, transcende essa compreensão e, portanto, deve ser reconhecido como uma estratégia fundamental para o exercício da cidadania (CARVALHO et al., 2016). Como diz Ladislau Dowbor (2002), a educação tem um papel determinante sobre o desenvolvimento humano e, certamente, para isso, é preciso a escola ensinar o indivíduo a pesquisar, a buscar novos conhecimentos e oportunidades, de modo a oferecer uma educação que viabilize ao cidadão ter consciência de seus deveres e direitos (GADOTTI, 2000).

A educação é um direito social garantido a todos e encontra-se inserida na Constituição pretérita como um dos direitos fundamentais para o alcance do desenvolvimento humano e o preparo para o exercício da cidadania (BRASIL, 1988 ). É importante destacar que, além da previsão constitucional quanto aos direitos à educação, outros documentos legislam a esse respeito, entre eles: o Pacto Internacional sobre os Direitos Econômicos, Sociais e Culturais, de 1966; a Lei de Diretrizes e Bases da Educação Nacional (Lei n. 9.394/96); o Estatuto da Criança e do adolescente (Lei n. 8.069/90); e o Plano Nacional de Educação (Lei n. 13.005/14).

Nessa perspectiva, é mister destacar que a solidariedade entre instituições, gestores e atores educacionais deve ser valorizada e estimulada para superar desafios e barreiras que dificultam a adoção de medidas e procedimentos num ritmo que atenda às necessidades prementes de uma participação cidadã por parte do próprio escolar. 
Dessa forma, como visto, percebe-se que na escola, quando em sintonia com as transformações sociais, os avanços na noção de cidadania deveriam solicitar avanços nas concepções e práticas de educação, entendida também como lugar de formação indissociável de um exercício da cidadania (CUNHA; DANI, 2008).

Nada obstante ao que foi dito, na seara da multiplicidade da participação no processo político, não se pode perder de vista que a devida notoriedade deve ser atribuída às noções de pluralismo jurídico, reconhecido como um novo referencial teórico-prático, cuja materialização ocorre nas múltiplas formas de manifestações societárias.

Sob o paradigma do pluralismo jurídico, direitos humanos e interculturalidade, como registra Wolkmer (2001), faz-se necessário destacar as novas formas de participação e emancipação políticas dos grupos sociais, a contar, inclusive, pelas crianças e adolescentes. Como sustenta o autor, então, o novo Pluralismo Jurídico pode ser caracterizado como uma "democracia judicial" de tal forma que se opõe ao monismo, sendo o pluralismo jurídico, portanto, a representação da multiplicidade de pensamentos, realidades, culturas, filosofias e todos os outros traços que influem na produção jurídica.

\section{CONSCIÊNCIA POLÍTICA E PARTICIPAÇÃO CIDADÃ}

Em um contexto de ampliação da democracia no Brasil, bem como da participação política, é de suma importância levar em consideração as expectativas que agucem o interesse dos estudantes de nível fundamental principalmente, pelos valores sociopolíticos presentes em seu processo de qualificação tanto como cidadãos quanto escolares. Nesse cenário, segundo Barroso (2015), a Constituição Cidadã refletiu um momento de otimismo e pujança no que diz respeito à concreção de direitos, sejam eles individuais ou sociais abrangendo, sobremaneira, os direitos e garantias fundamentais.

Há, na sociedade atual, um repertório teórico e mesmo prático que se liga ao conceito de cidadania, cuja amplitude acompanha o próprio desenvolvimento das sociedades modernas. No entanto a amplitude desses direitos à totalidade da população ainda não assegurou a garantia da liberdade e da igualdade tanto idealizadas por Rousseau (2005). Isso revela, portanto, que, quando da análise da completude da efetivação dos direitos e 
garantias fundamentais em solo pátrio, grandes desafios ainda estão postos, a contar pelo negligenciamento de muitas obrigações constitucionalmente asseguradas.

A cidadania, como reflexo de todo esse contexto, de fato, só pode se estabelecer por meio de instigada luta cotidiana por direitos e pela garantia daqueles que já existem. Para tanto, há a necessidade de essa luta ser apoiada em todos os âmbitos sociais. Mais do que isso, notamos maior preocupação com a difusão desses direitos, seja por meio de educação formal, seja pelos meios de comunicação. Programas de televisão debatem temas como violência, habitação, saúde, educação e outros direitos básicos. Livros didáticos e paradidáticos fomentam a discussão sobre o status de cidadão e os direitos humanos; outros associam ao desenvolvimento da cidadania uma discussão sobre os meios de comunicação e o próprio Capitalismo (DALLARI, 2015; COVRE, 2006).

O interesse em exercer a cidadania, melhorar as políticas públicas, gostar de implicar-se com assuntos públicos e defender seus interesses em situações de conflito, portanto, foram atitudes almejadas pelo projeto em questão em relação aos escolares. Pois, a partir do entendimento, pelo estudo da Constituição Federal, de conceitos relacionados à cidadania participativa, é que se cria uma base para questões que envolvem a eficácia política, identidade coletiva e vontade de agir coletivamente.

Entretanto é necessário destacar que a consciência política é formada a partir de diversos fatores relacionados a cada indivíduo em particular. Para a análise da consciência política, é necessário destacar que esta ocorre na interseção entre os fatores estruturais, as relações sociais interativas, as visões de mundo com seus preconceitos de fundo cultural e as suas reflexões conscientes de custos e benefícios de participar (SANDOVAL, 1989). Assim, sua formação ocorre em um processo psicossociohistórico da vida dos sujeitos, atuando de modo diversificado, de acordo com a complexidade da realidade de cada um (SILVA, 2001).

Outro ponto importante que o ensino da Constituição nas escolas deve influenciar e ensejar debates, é o de que, mesmo tendo a consciência de que alguns dos direitos propostos não são efetivados na prática e de que algumas estruturas sociais já estão fortemente enraizadas, os pressupostos 
da naturalidade da estabilidade social, estratificação social, hierarquia social, desigualdade, legitimidade de autoridade e reciprocidade entre as camadas sociais podem influenciar no processo de conscientização política e atuar como mecanismo de controle social, limitando o potencial de ação dos sujeitos (SANDOVAL, 1989).

Assim, a aceitação espontânea desses pressupostos por parte do indivíduo pode acarretar numa postura conformista dele por the faltar "Instrumentalização intelectual para um raciocínio sistemático e crítico" (SILVA, 2001, p. 108). Esse conformismo com relação à situação em que se encontra foi o que se pretendeu se repelido e questionado a partir da execução do projeto em questão, que teve como métodos para o alcance dos objetivos traçados os que se demonstram a seguir.

\section{METODOLOGIA}

A escolha do tema e do campo da pesquisa ocorreu a partir das discussões nas reuniões do grupo do Programa de Educação Tutorial (PET), modalidade interdisciplinar, atuante no campus Ministro Petrônio Portela em Teresina, PI. A ideia de contribuir para a democratização do ensino jurídico, em escola pública de Teresina, fez nascer o projeto e motivou as discussões acerca da imprescindibilidade da reflexão do ensino da Constituição Cidadã.

Após o embasamento teórico e debates, marcado por leituras sistemáticas e análises documentais da temática em comento, o projeto seguiu a trajetória institucional. Depois de aprovado, definiu-se que este seria desenvolvido na unidade de ensino selecionada pela 20ạ Gerência Regional de Educação (GRE), por ser o órgão responsável pela supervisão dos trabalhos desenvolvidos na Rede Pública Estadual de Educação e pelo conhecimento que tinha sobre o cotidiano das escolas.

A instituição escolhida foi o Centro de Ensino Integral Maria Melo, situado no bairro Planalto Ininga, na zona leste da cidade de Teresina, PI, o qual atende jovens do ensino fundamental e médio. O projeto foi apresentado e discutido com a direção e grupo pedagógico da escola que, prontamente, manifestaram interesse em colaborar na pesquisa e indicaram a inclusão dos escolares do 9o ano do ensino fundamental, pela disponibilidade de tempo que estes tinham para as ações do projeto. Dessa forma, já em sala 
de aula, foi aberto um diálogo com professores e alunos do 9으 ano para a construção de um calendário, definindo dia e horário para a realização das atividades programadas.

Finda a fase de conhecimento das diretrizes que norteavam o projeto, os 24 alunos do 9o ano do ensino fundamental, com idade entre 15 e 18 anos, foram convidados a fazer parte do estudo. Procurou-se atender as normas éticas para pesquisas com seres humanos, de acordo com a Resolução n. 466/12 da Comissão Nacional de Ética, que estabelece participação voluntária, anônima, integridade total dos participantes da pesquisa e liberdade de recusar e/ou abandonar a participação na investigação (BRASIL, 2012). Portanto, após os devidos esclarecimentos, os alunos foram convidados a participarem voluntariamente da pesquisa e, ao concordarem , o responsável legal assinou o Termo de Consentimento Livre e Esclarecido (TCLE), e os adolescentes assinaram o Termo de Assentimento Livre e Esclarecido.

Em seguida, sempre assistidos pelo professor da disciplina de Física, que acompanhou o desenrolar do projeto assiduamente, bem como toda a coordenação pedagógica da escola, foi aplicado o questionário, com questões objetivas e subjetivas, com o intuito de identificar, previamente, os conhecimentos dos escolares acerca dos direitos e garantias fundamentais, presentes na Constituição Federal de 1988.

$\mathrm{Na}$ investigação de abordagem qualitativa utilizaram-se os pilares da pesquisa-ação, isto é, a pesquisa com base empírica concebida e realizada em estreita associação com uma ação ou com a resolução de um problema coletivo conforme a proposta de Thiollent (1985). Além disso, procurou-se observar e conhecer a realidade dos alunos nas atividades cotidianas em sala de aula, suas dificuldades e possibilidades, visando interpretar e compreender os fenômenos desvelados pelos sujeitos no momento da cena investigada.

Segundo Haydt (1998), a partir da observação direta, cuidadosa, sistemática e com registro dos fatos como realmente ocorrem pode-se obter informações úteis e dados significativos sobre o aluno e sua aprendizagem. A ideia de usar essas técnicas ajudou a obter as informações necessárias para, a partir daí, descobrir as melhores estratégias de ensino-aprendizagem a serem utilizadas com os educandos para o entendimento dos direitos fundamentais e o preparo das ações de intervenção educativa. 
Assim, foi possível escutar os estudantes para entender objetividade, de tal sorte que, nos encontros iniciais, foi proposta uma série de atividades lúdicas, além de momentos que fomentaram discussões e problematizações que tocam a realidade e cujo raio de incidência teve ampla conexão entre a existência de direitos e sua efetivação na prática social. Nesse diapasão, para melhor contribuir com o processo de transformação da realidade, adotaram-se aspectos da proposta de Paulo Freire (1996) em favor da autonomia dos escolares.

Na sequência, deu-se início à ação educativa para trabalhar a temática dos direitos fundamentais. Em sala de aula, foram realizados 10 encontros, uma vez por semana, durante as aulas da disciplina de Física, com duração de 50 minutos, tendo como referência a cartilha Constituição em Miúdos e a própria Constituição Federal. O professor responsável pela disciplina participou de todos os encontros, incentivando os educandos e auxiliando na utilização das dinâmicas.

Nas intervenções educativas, foram utilizadas várias técnicas, como filmes e documentários, a exemplo do curta "Origem da Constituição de 1988", produzido pelo Senado Federal. Além disso, trabalhou-se com formulação de questões, repetição de palavras e produção de cartilhas para auxiliar o aprendizado, fixação dos conteúdos abordados e promoção de reflexões durante as atividades. As questões eram formuladas para estimular a participação dos alunos, bem como instigá-los à elaboração de novos questionamentos. Concomitantemente, ocorriam diálogos com a coordenadora pedagógica da escola, oportunidade na qual se acompanhava o rendimento dos alunos e as dificuldades enfrentadas no âmbito sócio escolar.

\section{RESULTADOS E DISCUSSÃO}

A amostra foi constituída de 24 alunos, média de idade dos entrevistados foi de 15,5 anos, com mínima de 15 e máxima de 18 anos, sendo 11 meninas e 13 meninos. A investigação partiu de quatro categorias, quais sejam, Constituição vigente do País (categoria 1), direitos e deveres (categoria 2), cidadania participativa (categoria 3) e justiça (categoria 4), refletidas na compreensão dos alunos sobre cada um desses itens do questionário, conforme quadro 1. 


\begin{tabular}{|l|c|c|}
\hline \multirow{2}{*}{ Descrição da pergunta } & \multicolumn{2}{c|}{ Percentual das respostas (\%) } \\
\cline { 2 - 3 } & Sim & Não \\
\hline $\begin{array}{l}\text { Você já leu ou manuseou (folheou) a } \\
\text { Constituição Federal do Brasil? }\end{array}$ & 20 & 80 \\
\hline O que você entende por uma Constituição? & 20 & 80 \\
\hline O que você entende por cidadania? & 94 & 6 \\
\hline O que você entende por direitos e deveres? & 56 & 44 \\
\hline O você entende por justiça? & 50 & 50 \\
\hline
\end{tabular}

Quadro 1 - Número e percentual de respostas dos escolares em relação à compreensão das categorias: cidadania, constituição, direitos/deveres e justiça, Teresina, 2016.

Pode-se observar que, em geral, os estudantes não estavam a par dos assuntos tratados, demonstrando pouco ou nenhum conhecimento sobre os seus direitos e garantias fundamentais. Na questão inicial formulada sobre se tinham ou tiveram contato com a Constituição vigente, a maioria (80\%) dos entrevistados respondeu que não. Como surpresa, esse índice foi maior entre aqueles com idades mais avançadas, ou seja, quase $100 \%$ dos estudantes entre 17 e 18 anos não tinham conhecimento acerca da constituição, justiça, direitos, deveres e cidadania participativa.

Assim é verdade que, quando indagados a respeito se conheciam a Constituição Federal de 1988, a ampla maioria (80\%) dos entrevistados respondeu não saber do que se tratava muito menos do seu conteúdo. O silêncio e desconhecimento acerca da matéria mostraram-se notório, demonstrando ser esta um problema de natureza política e social. É na Constituição vigente que estão contidos direitos e deveres mínimos de qualquer cidadão brasileiro, tais como as liberdades individuais e coletivas; portanto, uma vez que os cidadãos não os conheçam se torna difícil reivindicá-los.

Ainda no âmbito da compreensão da Constituição Cidadã, ao serem questionados para detalhar mais sobre essa categoria, apenas poucos alunos conseguiram definir que, no referido documento, estavam às leis e mandamentos que norteiam toda a vida em sociedade. Disseram mais, é por meio da concretização dos direitos presentes nesse documento que o povo poderá exercer plenamente sua cidadania. 
No tocante as noções do que seria cidadania, incluindo o entendimento sobre direitos e deveres de qualquer cidadão, o grau de conhecimento dos escolares ganhou novas feições, pois se observou que a voz dos estudantes em algum momento mencionava um certo conhecimento do tema, com posicionamentos ativos e críticos. Reconheceram que são portadores de direitos e deveres, haja vista que integram uma comunidade política, e que, inerente a esta, as normativas disciplinam a conduta humana. Além do mais, os jovens escolares conseguiam relacionar problemas práticos, inclusive corriqueiros em suas vidas, com aquilo que preconizava a Constituição.

Seguindo os relatos da compreensão do conceito de cidadania, chamou a atenção o fato de que $94 \%$ dos pesquisados responderam no sentido que se segue: "cumprir com obrigações e ter direitos"; "respeito às leis"; "promover transformações na comunidade onde se convive". Isso, de certa maneira, demonstra a capacidade dos escolares de refletirem sobre qual papel desempenham na sociedade atual, uma vez que se colocam como sujeitos e sujeitas de direitos e, ao mesmo tempo, capazes de se identificarem como interpretes da realidade sociojurídica.

Assim, pode-se observar que, mesmo sem total consciência, os alunos apresentam a capacidade de conhecimento do que é ser "sujeito de direito", como centros subjetivos de direito ou dever, ou seja, tudo aquilo que o direito reputa apto a ser titular de direito ou devedor de obrigações.

A partir da análise final do questionário, como passo inicial para o planejamento das atividades educativas do projeto, ficou claro que, para a maioria das temáticas trazidas, os escolares não apresentaram respostas densas e pertinentes, especialmente no conceito de justiça, que teve respostas esparsas. Verificou-se, nas justificavas de respostas a essa questão, que uma parcela considerável não sabia definir o que era justiça e ninguém apresentou resposta concreta de como proceder para praticar justiça na vida cotidiana das pessoas, configurando-se desconhecimento acerca dessa categoria.

Tal realidade é um tanto quanto preocupante, visto que, na Carta Política de 1988, encontra-se presente um vasto rol de direitos e garantias fundamentais, que, uma vez conhecidos, possibilita aos seus destinatários a reivindicação, além de torná-los minimamente conscientes de sua participação no ambiente democrático. 
Embora seja visível a falta de conhecimento acerca das noções de cidadania participativa e responsável por parte dos escolares, em determinadas situações, especialmente no descontentamento com as condições precárias na qual a escola se encontrava, eles demonstraram preocupação e indignação com a inércia do Estado na promoção de direitos mínimos. As maiores inquietações giravam em torno da estrutura física do ambiente escolar que não apresenta melhorias, bem como da alimentação escolar oferecida. Os escolares apresentavam em suas falas uma preocupação com a inexistência de planos e cuidados no cotidiano escolar, no sentido de adotar medidas que viabilizassem uma melhor qualidade do ambiente e da alimentação. Preocupavam-se, portanto, com a própria gestão da escola, mostrando-se conscientes de que muitos dos problemas devem ser resolvidos pelos responsáveis superiores.

A partir do questionário aplicado aos alunos e das análises feitas na escola, percebeu-se a necessidade de buscar alternativas que proporcionassem um maior envolvimento e aprendizado do público alvo sobre os direitos fundamentais. Nessa perspectiva, foram trabalhados os temas que se seguem: Poema "O Bicho", de Manoel Bandeira (1982); Direito à Educação, Saúde e Lazer; Vedação ao Trabalho Escravo; Liberdade de Expressão e Religiosa; Direito à Igualdade, e outros mais. Quando havia dificuldade para o entendimento dos conteúdos, buscava-se esclarecer as dúvidas de forma fácil e pedagógica, usando-se a cartilha "Constituição em Miúdos", produzida pelo Senado Federal em conjunto com Assembleia Legislativa de Pouso Alegre, Minas Gerais (BRASIL, 2016).

No mais, a proposta foi bem aceita, e todos os escolares se mostraram interessados em saber sobre o dever do Estado na efetivação dos direitos e garantias fundamentais, dentre os quais são beneficiários diretamente, como o direito à educação, moradia, lazer, transporte e saúde.

Certamente, o conhecimento da realidade descrita acima é fundamental, cabendo às autoridades públicas estaduais fazer cumprir os direitos constitucionalmente assegurados. Há necessidade de encontrar caminhos alternativos que cooperem para a construção de soluções e, consequentemente, superação dos desafios no contexto escolar acerca dos problemas cotidianos que os escolares enfrentam. Deve-se lembrar que a educação 
é capaz de tornar o sujeito preparado para participar da vida social como cidadão (ROUSSEAU, 2014). O desconhecimento de direitos individuais e coletivos origina postura de sujeitos não cidadãos, em que não participam da tomada de decisões e são omissos na participação da vida em sociedade (DALLARI, 2015).

O trabalho integrado entre escola, Estado e família é essencial e precisa ser enfatizado para que cada segmento desenvolva suas responsabilidades. A educação, direito de todos e dever do Estado e da família, será promovida e incentivada com a colaboração da sociedade. Desta forma, poderá alcançar o pleno desenvolvimento da pessoa, seu preparo para o exercício da cidadania e sua qualificação para o trabalho, claramente expresso no artigo 25 da Constituição Brasileira vigente (BRASIL, 1988).-

Dessa forma, é natural que, em um trabalho conjunto, no qual cada responsável desempenhe o seu papel, novas soluções possam ser encontradas acerca das questões levantadas. Como é cediço, a maneira como se transmite o conhecimento, principalmente quando se trata de matéria jurídica e, ainda mais, quando se tem como destinatários jovens escolares, a metodologia a ser adotada se mostrou imprescindível. Foi fundamental a adoção de uma metodologia compartilhada, a favor do diálogo participativo e reflexivo, permitindo aos escolares o reconhecimento como sujeito de direito indubitavelmente, integrantes ativos do processo de conhecimento. De certa forma, favoreceu a participação política e administrativa de todos os segmentos da comunidade escolar de forma efetiva na formação da democracia. Como preconiza Freire (1996), ao se estabelecer metodologias ao processo de aprendizagem direcionada para a libertação do conhecimento e autonomia pedagógica, criam-se possibilidades para que o aprendiz se compreenda como sujeito de sua própria história e busque alternativas e estratégias para a resolução dos problemas apresentados.

Como afirma Garrido (2000, p. 45)

No diálogo, as ideias vão tomando corpo, tornando-se mais precisas. O conflito de pontos de vista aguça o espírito crítico, estimula a revisão das opiniões, contribui para relativizar posições [...]. É neste momento do diálogo e da reflexão que os alunos tomam consciência de sua atividade cognitiva, dos procedimentos de investigação que utilizaram aprendendo a geri-los e aperfeiçoá-los. 
O projeto Educação Jurídica na escola se destacou como pioneiro na sua proposta de trabalho, justamente por oportunizar aos jovens escolares um primeiro contato com a Constituição Cidadã, pois procurou despertar-lhes a visão crítica necessária ao reconhecimento tanto dos seus direitos como seus respectivos deveres. Como afirma Mendonça e Silva (2002), poucos têm acesso direto aos conhecimentos gerados na universidade, e a extensão universitária é um importante instrumento de democratização do acesso a esses conhecimentos e impulsionadora de lutas sociais para a transformação da realidade. Os movimentos e as lutas sociais em busca do direito ao acesso ao conhecimento e da aproximação da universidade com a comunidade escolar possibilitam uma formação mais humanizada do estudante universitário, e ajudam no alcance da garantia da educação para todo ser humano e, consequentemente, auxilia na superação das desigualdades existentes em torno da conquista da educação de qualidade.

Vale destacar, ainda, que nessa função, ou seja, quando a universidade se envolve em atividades comunitárias, esta reforça e renova o seu papel no desenvolvimento econômico e social, dirigindo seus interesses para a resolução das questões demandadas pelos setores fragilizados da sociedade alicerçada pela democracia (CARVALHO et al., 2013; CARVALHO et al., 2016).

Em sentido semelhante, as práticas extensionistas de outros projetos no contexto do PET, desenvolvem ações semelhantes, a exemplo do Projeto Educação, Direitos Humanos e Inclusão Social, na Universidade Federal do Piauí, campus de Teresina, com grupos de natureza coletiva e interdisciplinar, com intervenções voltadas para consagrar o que preconiza a Constituição vigente do Brasil.

\section{CONSIDERAÇÕES FINAIS}

O projeto Ensino jurídico na escola é uma experiência de aproximação entre a universidade e escola, marcada pela horizontalidade das informações. Proporcionou aos escolares do ensino fundamental uma aproximação com a universidade e a oportunidade de experimentar novas realidades, e aos acadêmicos, a oportunidade ímpar de instrumentalizar conhecimentos adquiridos em sala de aula. É a concretização do novo modelo universitário, pautado nas ações integradas e indissociáveis entre ensino, pesquisa e extensão. 
É inegável, portanto, que a democratização do ensino jurídico para além das vivências da academia constitui, também, manifestação de exercício da cidadania participativa e responsável. Em um processo de retroalimentação, em que a aprendizagem é dialógica e recíproca, para os acadêmicos a experiência foi engrandecedora e construtiva para suas formações. No mesmo sentido, aos escolares do 9ㅇa ano, embora durante o transcurso do projeto se sentissem inseguros e pouco soubessem sobre seus direitos fundamentais e sociais, vozes ecoaram na descrição de situações de desrespeito a direitos constitucionalmente protegidos.

Cada ação realizada no projeto impactou positivamente nos próprios alunos que planejaram executá-la e na participação coletiva do grupo. A troca de conhecimentos e experiências com os escolares e o convívio com ideias e opiniões divergentes, revelaram a necessidade de uma constante revisão de literatura sobre o tema, bem como reforçaram o quanto é importante a extensão, com ações que levem o conhecimento acadêmico à comunidade, na formação do universitário e o interesse dos estudantes em desenvolver novos projetos, com enfoques diferentes, abrangendo, assim, outra parcela da sociedade.

\section{AGRADECIMENTOS}

Os autores agradecem ao FNDE/MEC, pela concessão das bolsas ao grupo.

\section{REFERÊNCIAS}

BANDEIRA, Manuel. Estrela da vida inteira. 9. ed. Rio de Janeiro: José Olympio, 1982. BARROSO, L. R. B. Curso de direito constitucional contemporâneo: os fundamentos constitucionais e a Constituição do novo modelo. São Paulo: Saraiva. 2015.

BOBBIO, N. Teoria geral da política. Rio de Janeiro: Campus, 2002.

BRASIL. Constituição em Miúdos. Brasília, DF: Senado Federal, 2016.

. Ministério da Saúde. Resolução n. 466/12. Conselho Nacional de Pesquisa com Seres Humanos. Diário Oficial da União, Brasília, 2012.

1988.

. Constituição da República Federal do Brasil. Brasília, DF: Senado Federal, 
BRESSAN, C. M. F.; COMERLATTO, D. (Org.). Políticas sociais e desenvolvimento: a interface com o serviço social. Passo Fundo: IMED, 2015. 111p.

BRITO, A. C. A. G.; LOPES, M. E. O papel da educação escolar para o exercício da cidadania. Revista Primus Vitam, São Paulo, n. 7, p. 3-14, 2014.

CANOTILHO, J. J. G. Constituição dirigente e vinculação do legislador: contributo para a compreensão das normas constitucionais programáticas. 1. ed. Coimbra, Portugal: Coimbra Editora, 1982. 539p.

CARVALHO, C. M. R. G. et al. Contribuições de uma extensão universitária participativa: uma proposta de educação para a cidadania. Extramuros - Revista de Extensão da UNIVASF, v. 4, n. 2, p. 54-65, 2016.

CARVALHO, C. M. R. G. et al. Educação e cidadania: uma experiência interdisciplinar na comunidade. Participação, Brasília, ano 13, n. 23/24, p. 17-24, 2013.

COVRE, M. L. M. O que é Cidadania. 3. ed. São Paulo: Brasiliense, 2006. (Coleção Primeiros Passos).

CUNHA, J. L.; DANI, L. S. C. (Org.). Escola, conflito e violência. Santa Maria: Ed. da UFSM, 2008.

DALLARI, D. A. Cidadania e direitos humanos. São Paulo: Brasiliense, 2015. (Coleção Polêmica).

DOWBOR, L. A reprodução social: tecnologia, globalização e governabilidade. Petrópolis, RJ: Vozes, 2002.

FREIRE, P. Pedagogia da autonomia: saberes necessários à prática educativa. São Paulo: Paz e Terra, 1996.

GADOTTI, M. Perspectivas atuais da educação. São Paulo em Perspectiva, São Paulo, v. 14, n. 2, p. 3-11, 2000.

GARRIDO, E. Sala de aula: espaço de construção do conhecimento para o aluno e de pesquisa e desenvolvimento profissional para o professor. In: CASTRO, A. D. C.; Anna, M. P. (Org.). Ensinar a ensinar: didática para a escola fundamental e médio. São Paulo: Pioneira; Thomson Learning, p. 125-41, 2000.

HAYDT, R. C. C. Avaliação do processo ensino-aprendizagem. São Paulo: Ática, 1988. MARTNS, M. J. D; MOGARRO, M. J. A educação para a cidadania no século XXI. Revista Iberoamericana de Educación, n. 53, p.185-202, 2010.

MENDONÇA, S. G. L.; SILVA, P. S. Extensão universitária: uma nova relação com a administração pública. Extensão Universitária: ação comunitária em universidades brasileiras, São Paulo, v. 3, p. 29-44, 2002.

MIGUEL, S. F. et al. Movimentos sociais, política e cidadania em perspectiva: 
aspectos da gestão territorial no Baixo Amazonas. Somanlu: Revista de Estudos Amazônicos, Manaus, ano 12, n. 2, p. 103-23, 2012.

PALMA FILHO, J. C. Cidadania e Educação. Cadernos de Pesquisa, São Paulo, n. 104, p. 101-21, 1998.

PINSKY, J; PINSKY, C. B. (Org.). História da Cidadania. 6. ed. São Paulo: Contexto, 2013.

ROUSSEAU, J. J. Discurso sobre a origem e os fundamentos da desigualdade entre os homens. 3. ed. São Paulo: Martins Fontes, 2005. 372p.

. Emílio ou da educação. 4. ed. São Paulo: Martins Fontes, 2014. 744p.

SANDOVAL, S. A. M. Considerações sobre aspectos micro-sociais na análise dos movimentos sociais. Psicologia e Sociedade, v. 4, n. 7, p. 61-72, set. 1989.

SILVA, A. S. Consciência e participação política: uma abordagem Psicopolítica. Interações, São Paulo, v. 6, n. 12, p. 69-90, jul./dez. 2001.

THIOLLENT, M. Crítica metodológica, investigação social e enquete operária. São Paulo: Polis, 1985.

WOLKMER, A. C. Pluralismo jurídico: fundamentos de uma nova cultura no direito. 3. ed. São Paulo: Alfa-Ômega, 2001. 
